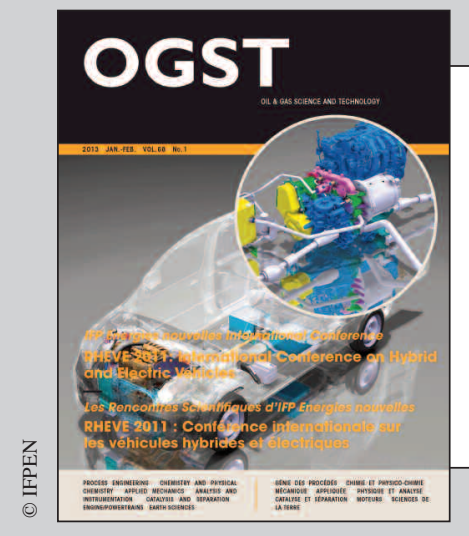

Dossier

This paper is a part of the hereunder thematic dossier published in OGST Journal, Vol. 68, No. 1, pp. 3-178 and available online here

Cet article fait partie du dossier thématique ci-dessous publié dans la revue OGST, Vol. 68, n 1 , pp. 3-178 et téléchargeable ici

DOSSIER Edited by/Sous la direction de : A. Sciarretta, F. Badin et J. Bernard RHEVE 2011 : International Conference on Hybrid and Electric Vehicles RHEVE 2011 : Conférence internationale sur les véhicules hybrides et électriques

Oil \& Gas Science and Technology - Rev. IFP Energies nouvelles, Vol. 68 (2013), No. 1, pp. 3-178

Copyright (C) 2013, IFP Energies nouvelles

\section{$3>$ Editorial}

$13>$ Analysis and Experimental Implementation of a Heuristic Strategy for Onboard Energy Management of a Hybrid Solar Vehicle

Analyse et expérimentation d'une stratégie heuristique pour la gestion d'énergie à bord d'un véhicule hybride solaire

G. Coraggio, C. Pisanti, G. Rizzo and M. Sorrentino

23 > Open Issues in Supervisory Control of Hybrid Electric Vehicles: A Unified Approach Using Optimal Control Methods

Questions ouvertes sur la supervision énergétique des véhicules hybrides électriques : une approche unifiée par la théorie de la commande optimale

L. Serrao, A. Sciarretta, 0. Grondin, A. Chasse, Y. Creff, D. Di Domenico, P. Pognant-Gros, C. Querel and L. Thibault

35 > Optimization of Hybrid Power Trains by Mechanistic System Simulations

Optimisation de groupes motopropulseurs électriques hybrides par simulation du système mécanique

T. Katrašnik and J.C. Wurzenberger

51 > A Phenomenological Heat Transfer Model of SI Engines - Application to the Simulation of a Full-Hybrid Vehicle

Un modèle phénoménologique de transfert thermique au sein de moteurs à allumage commandé - Application à la simulation d'un véhicule full-hybride

R. Dubouil, J.-F. Hetet and A. Maiboom

$65>$ Battery Electric Vehicle (BEV) or Range Extended Electric Vehicle (REEV)? - Deciding Between Different Alternative Drives Based on Measured Individual Operational Profiles

Véhicule électrique à batteries (BEV) ou véhicule électrique à prolongateur d'autonomie (REEV) ? - Choisir entre différents entrânements alternatifs sur la base de profils opérationnels individuels mesurés

S. Marker, B. Rippel, P. Waldowski, A. Schulz and V. Schindler

$79>$ Assessment by Simulation of Benefi ts of New HEV Powertrain Configurations

Évaluation par simulation des bénéfi ces de nouvelles chaînes de traction hybrides

N. Kim and A. Rousseau
95 > Dual Mode Vehicle with In-Wheel Motor: Regenerative Braking Optimization

Véhicule bi-mode avec moteurs roues : optimisation du freinage récupératif

G. Le Solliec, A. Chasse, J. Van-Frank and D. Walser

109 > Engine Downsizing and Electric Hybridization Under Consideration of Cost and Drivability

Réduction de taille moteur et hybridation électrique avec considérations de coût et de performance de conduite

S. Ebbesen, P. Elbert and L. Guzzella

117 > Representative Midwestern US Cycles: Synthesis and Applications Cycles représentatifs du Middle West américain : synthèse et applications

T.-K. Lee and Z.S. Filipi

127 > A Review of Approaches for the Design of Li-lon BMS Estimation Functions

Revue de différentes approches pour l'estimation de l'état de charge de batteries Li-ion

D. Di Domenico, Y. Creff, E. Prada, P. Duchêne, J. Bernard and V. Sauvant-Moynot

137 > Experimental Assessment of Battery Cycle Life Within the SIMSTOCK Research Program

Évaluation expérimentale de la durée de vie de la batterie dans le programme de recherche SIMSTOCK

P. Gyan, P. Aubret, J. Hafsaoui, F. Sellier, S. Bourlot, S. Zinola and F. Badin

$149>$ Smart Battery Thermal Management for PHEV Efficiency Une gestion avancée de la thermique de la batterie basse tension de traction pour optimiser l'efficacité d'un véhicule hybride électrique rechargeable

L. Lefebvre

$165>$ Parameterization and Observability Analysis of Scalable Battery Clusters for Onboard Thermal Management

Paramétrage et analyse d'observabilité de clusters de batteries de taille variable pour une gestion thermique embarquée

Xinfan Lin, Huan Fu, Hector E. Perez, Jason B. Siege, Anna G. Stefanopoulou, Yi Ding and Matthew P. Castanier 


\title{
Dual Mode Vehicle with In-Wheel Motor: Regenerative Braking Optimization
}

\author{
G. Le Solliec ${ }^{1 *}$, A. Chasse ${ }^{1}$, J. Van-Frank ${ }^{2}$ and D. Walser ${ }^{3}$ \\ 1 IFP Energies nouvelles, 1-4 avenue de Bois-Préau, 92852 Rueil-Malmaison Cedex - France \\ 2 Renault SA, 1 avenue du Golf, 78288 Guyancourt - France \\ 3 Michelin, Route André-Piller 30, 1762 Givisiez - Suisse \\ e-mail: guenael.le-solliec@ifpen.fr - alexandre.chasse@ifpen.fr - jean.van-frank@renault.com - daniel.walser@cd-michelin.ch \\ * Corresponding author
}

\begin{abstract}
Résumé - Véhicule bi-mode avec moteurs roues : optimisation du freinage récupératif Pour faire face au besoin croissant de mobilité des personnes et des biens tout en réduisant massivement les émissions de $\mathrm{CO}_{2}$, l'électrification des véhicules est une solution majeure. La grande variété des véhicules et de leur utilisation conduit à la mise en place d'architectures adaptées et donc de solutions innovantes. Cela est particulièrement le cas pour le développement de véhicules utilitaires dont l'objectif est de promouvoir un usage tout électrique en ville (véhicule zéro émission) tout en maintenant une autonomie significative pour un usage extra-urbain. Le projet VelRoue, un partenariat entre Renault, Michelin et IFP Energies nouvelles, a pour objectif le développement d'un véhicule utilitaire bi-mode utilisant un groupe motopropulseur thermique traditionnel sur le train avant et des moteurs roues sur le train arrière. Chaque système de propulsion sera alors séparément optimisé à son utilisation pour permettre d'atteindre un faible niveau global d'émissions de $\mathrm{CO}_{2}$ sur un usage mixte. En plus de ces spécificités et avantages pour l'usage d'un véhicule utilitaire, nous nous attacherons également à montrer l'intérêt d'une telle architecture pour optimiser le freinage récupératif tout en conservant un comportement dynamique sécurisant.
\end{abstract}

\begin{abstract}
Dual Mode Vehicle with In-Wheel Motor: Regenerative Braking Optimization - To meet the growing need for mobility of people and goods while massively reducing $\mathrm{CO}_{2}$ emissions, the electrification of vehicles is an essential solution. The variety of vehicles and their use results in innovative solutions for adapted architecture. This is especially true for light commercial vehicles where the objective is to promote full electric use in urban conditions (zero emission vehicle) while maintaining significant range autonomy on road. The project VelRoue, a partnership between Renault, Michelin and IFP Energies nouvelles, aims to develop a dedicated dual-mode vehicle using a conventional thermal powertrain on the front axle and in-wheel motors on the rear one each powertrain to its use and makes it possible to achieve a low level of homologation $\mathrm{CO}_{2}$ emissions. In addition to features that meet the specific use of a commercial vehicle, in this paper we will particularly demonstrate the benefit of such an architecture to optimize the regenerative braking while ensuring a safe dynamic behaviour.
\end{abstract}




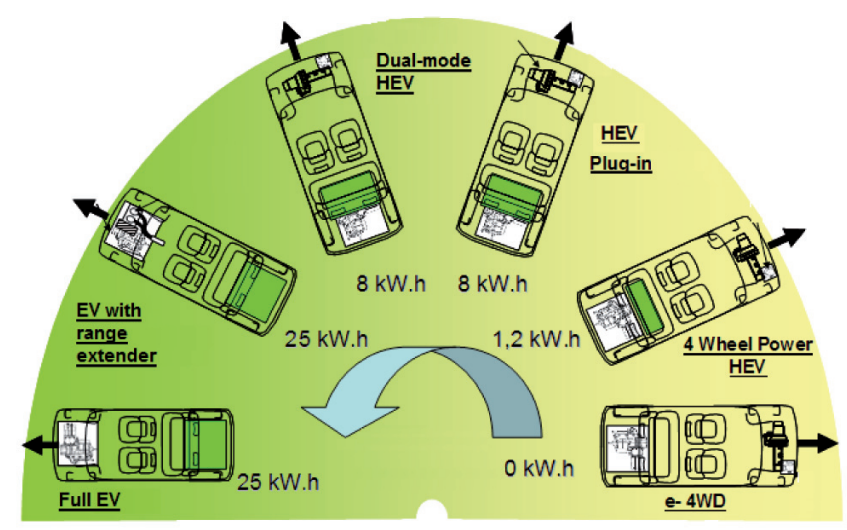

Figure 1

Different architectures for electrified vehicles.

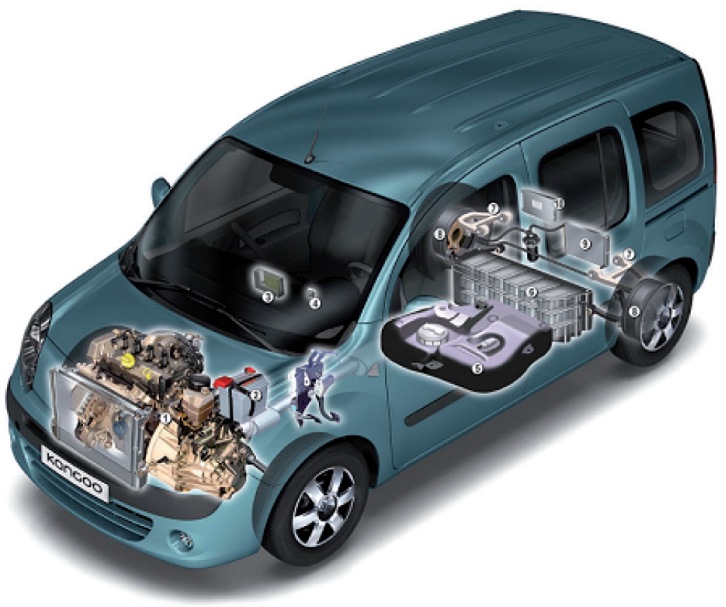

Figure 2

Dual mode vehicle with in-wheel motors.

\section{INTRODUCTION}

In the context of a massive reduction in $\mathrm{CO}_{2}$ emissions related to the mobility of persons and goods, vehicle electrification is one of the most effective solutions in combination with a production of "clean" electricity. This breakthrough technology can be deployed in different ways, from a micro hybrid with an electric start \& stop system to full electric vehicles (Fig. 1). This variation of architectures is justified by a proper adaptation of vehicles to different societal uses as well as infrastructure needed for plug-in vehicles.

The VelRoue project, a partnership between Renault, Michelin and IFP Energies nouvelles funded by the ADEME ${ }^{1}$ in the framework of the $\mathrm{AMI}^{2}$ program, aimed to develop an architecture tailored to the needs of a light commercial vehicle, such as the Renault Trafic or Kangoo. The choice was made for a dedicated dual mode architecture using in-wheel motors on the rear axle. This solution combines the advantages of an electric vehicle in urban conditions (no pollutants, $\mathrm{CO}_{2}$ emissions and noise), with a significant preservation of the range autonomy of a conventional thermal vehicle while offering a competitive price compared to full electric vehicles. Many technological issues related to the use of in-wheel motors had to be address, such as their integration and impact on vehicle dynamics. Control and supervision of both powertrains had to be developed taking into account the desired performance (energy management, $\mathrm{CO}_{2}$ emissions, dynamic) and safety operation.

In the first section, this architecture and the impact of requirements on individual component design will be discussed. The second one will present the vehicle simulator used for

(1) Agence De l'Environnement et de la Maîtrise de l'Energie.

(2) Appel à Manifestation d'Intérêt. development and validation of supervision and control strategies. We will then focus on one valuable feature of the use of in-wheel motors: namely the new prospects of regenerative braking optimization and wheel slip control due to the proximity of the electrical motors to the wheel. Section 3 will then present how the supervisor can integrate all the constraints to optimize the use and coordination of all the actuators and Section 4 how the use of in-wheel motors can improve estimation and control of road friction.

\section{DUAL MODE ARCHITECTURE}

\subsection{Objectives}

With currently available technologies, the deployment of plug-in electric vehicles is widely being considered for urban use in order to reduce $\mathrm{CO}_{2}$ emissions. However, the limit of range imposed by the current battery capacity makes them less suitable for extra-urban use. The objective here is to develop a dual-mode architecture particularly suited to the needs of small commercial vehicles users. The vehicle must be comparable to a plug-in electric vehicle $\left(\mathrm{ZEV}^{3}\right)$ in urban use, to a combustion engine vehicle in suburban use and global optimization of the architecture should allow for very low $\mathrm{CO}_{2}$ emissions and a competitive price compared to electric vehicles. The dual-mode solution is based on the development and optimization of two separate powertrains dedicated to each use (Fig. 2):

- a thermal driving mode with a conventional thermal powertrain on the front axle;

- an electric driving mode with two in-wheel motors on rear wheels.

(3) Zero Emission Vehicle. 
This innovative concept will be validated on a Renault Kangoo demonstration car. The simultaneous use of both powertrains will be limited to a minimum. When the driver chooses the electric mode, the engine will still be stopped. If the battery is discharged, the customer will be informed of the need to switch to thermal mode. In this mode, the driver will have a conventional thermal vehicle equipped with a robotized gearbox, except for certain operations where the use of both powertrains will be imposed for optimization. For example, during vehicle pull-away or acceleration requests, electric motors will assist the engine to prevent the gearbox from downshifting. Similarly, during deceleration and braking, the electric motors will be used for regenerative brake.

Limiting ZEV mode to urban use allows for the adaptation of required battery capacity compared to a fully electric vehicle, with the ability to then reduce its volume and cost. On the other hand, the use of an in-wheel motor, less intrusive than a motor mounted on a powertrain as in a hybrid vehicle, can reduce the cost of platform adaptation and maintain relevant cargo volume, essential in the case of a commercial vehicle.

This dual-mode architecture therefore represents an attractive economic alternative significantly reducing $\mathrm{CO}_{2}$ emissions, with a target at $40 \mathrm{gCO}_{2} / \mathrm{km}$ on NEDC cycle, while maintaining a large cargo volume.

\subsection{Thermal Powertrain}

The dedicated thermal powertrain on the front axle must be optimized for road and highway use with a limited cost. The purpose was not to design specific components, but to adapt existing ones.

\subsubsection{Engine}

The candidate engine must have good efficiency at medium and high loads. A supercharged spark-ignition engine meets this requirement and the selected engine is a Renault D4Ft with a displace volume of 1.2 liters. Supercharging can reduce consumption without incurring significant additional costs but with two drawbacks: the need to manage the tradeoffs between high and low load performances and thermal limitations at high loads resulting in over consumption.

At high loads, the thermodynamic conditions during combustion cause the emergence of knock phenomenon potentially destructive to the cylinders. This is usually prevented by delaying the combustion with spark advance. However, when this is done the combustion phasing is no longer optimal and reduces engine efficiency, increasing consumption and reducing engine performances. The use of E85 fuel (more than $85 \%$ of ethanol) has a main advantage for this application. Its octane number, representative of knock resistance, is much higher than a standard gasoline fuel. It is

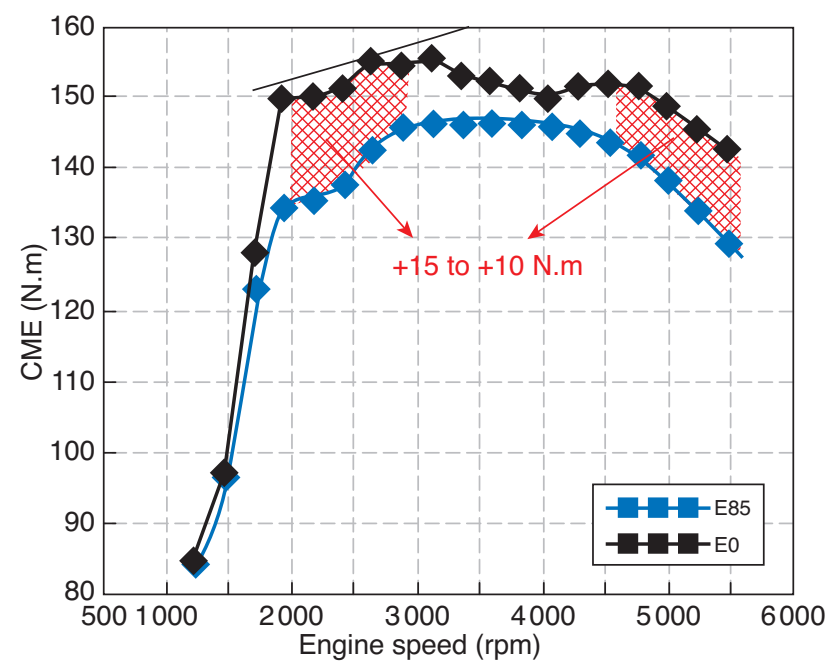

Figure 3

Maximum torque of D4Ft engine with E0 and E85 fuel.

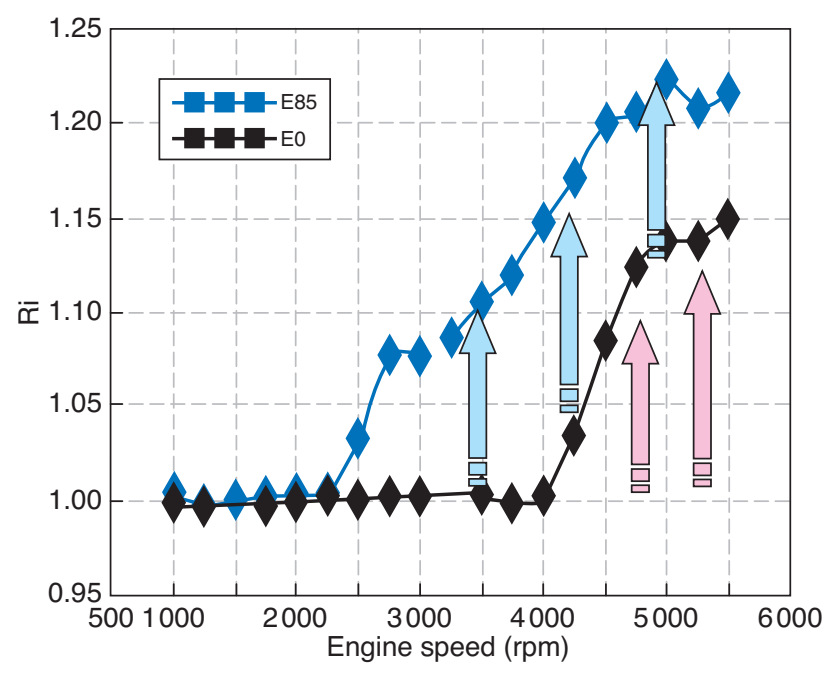

Figure 4

Equivalent ratio at full load with E0 and E85 fuel.

therefore possible to keep optimal combustion over the entire operating range, while retaining minimum consumption and improving engine performance (Fig. 3).

In order to prevent damage on a three-way exhaust catalyst, one needs to control and limit its upstream temperature. Delaying combustion at high loads to prevent knock ignition will increase exhaust temperature. It is usually prevented by increasing injected mass more than needed to get stoichiometric conditions, with directly increased consumption at those loads. Using E85 to prevent knock will then naturally reduce the need of increasing injected fuel (Fig.4). 


\subsubsection{Robotized Gearbox}

The dedicated gearbox chosen for this project is a Renault JH3 with a robotized clutch and selectors. Optimization of engine specific consumption and performances at high loads permits the consideration of longer gear ratios (Tab. 1), which leads to the additional reduction of vehicle fuel consumption and $\mathrm{CO}_{2}$ emissions.

\section{TABLE 1}

Gearbox ratio

\begin{tabular}{c|c|c|c|c|c}
\hline Gear & 1 & 2 & 3 & 4 & 5 \\
\hline Ratio & 3.73 & 2.05 & 1.39 & 1.03 & 0.74 \\
\hline
\end{tabular}

The second gear is specifically dedicated for pull-away with the assistance of electric motors to push the vehicle. The first gear will then be used only in back-up mode when electric propulsion is not available (low battery state of charge, motor malfunction, etc.).

In order to offset the lack of engine torque at low engine speeds and to prevent gearbox downshifts during acceleration requests, electric motors will also assist the front powertrain.

\subsection{Electric Powertrain}

The dedicated electric powertrain on the rear axle must be optimized for urban use. The introduction of in-wheel motors in the automotive sector requires specific design and study, taking into consideration the constraints involved with inwheel integration as well as the impact on the dynamic behaviour and vehicle operation safety.

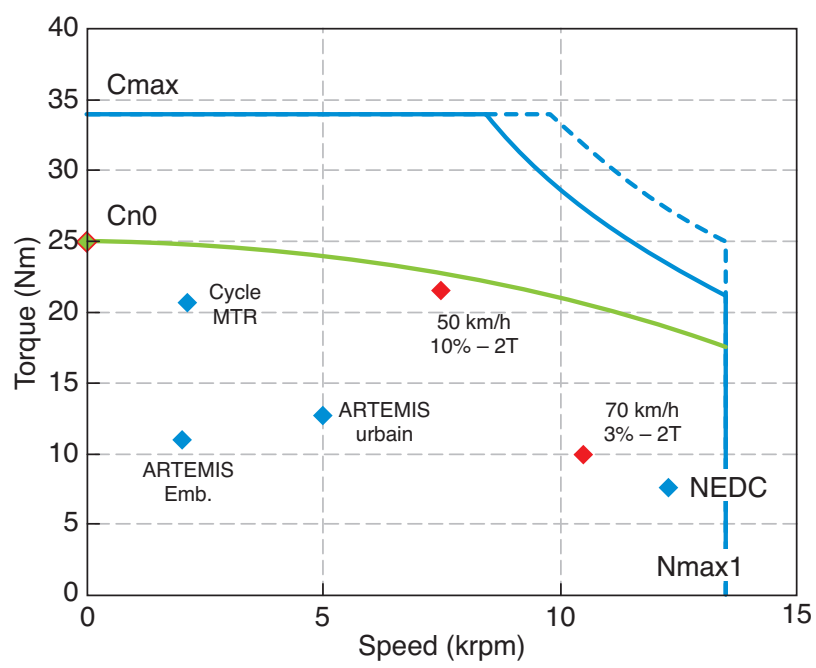

Figure 5

Operating range of in-wheel motors.

\subsubsection{Electric Motors}

Electric motors and associated reduction were strictly sized for urban use with a maximum operating speed of $90 \mathrm{~km} / \mathrm{h}$ and a maximum torque corresponding to that required to pull the vehicle away in all conditions. In addition, main operating points of different considered cycles (NEDC, ARTEMIS urban and MTR) must fall within the field of continuous operation. Considering those requirements, dimensioning data have been chosen:

- $R=17$ (reduction ratio);

- $C_{\max }=34 \mathrm{Nm}$;

- $C_{\mathrm{n} 0}=25 \mathrm{Nm}$;

- $N_{\max }=13.6 \mathrm{krpm}$.

It enables the design of a specific electric machine with an adapted operating range (Fig. 5). This optimal design limits the size of the motors, facilitates their implementation, limits their costs and is able to get optimal efficiency on operating points at low loads. This design has been validated on a MTR cycle consisting of successive transients in torque and speed in order to stress the motor and check its temperature stability.

\subsubsection{Dog Clutch}

The maximum speed limit for urban use requires the integration of a dog clutch to disengage motors at high speeds and to prevent damage. It also ensures the safe operation of the vehicle. Indeed, in case of malfunction of either one wheel motor or the control system, the opening of clutches will ensure that no differential torque is applied to the rear axle, which could destabilize the vehicle.

Two main drawbacks had to be addressed to design the clutches and the associated controller (Fig. 6):

- ability to disengage motors in at least $500 \mathrm{~ms}$ to ensure vehicle stability in case of malfunction;

- ability to disengage motors under torque in case of shortcircuits.

\subsubsection{In-Wheel Integration}

The architectural interest of in-wheel motors is to outsource their integration of the vehicle body. The main drawback is then integration in a restricted volume of motor, reduction, dog clutch and brake, while taking into account the constraints of assembly and maintenance. This set will be subject to internal thermal stresses (mainly due to braking) and external vibrations related to the road, shocks (mounted sidewalks, manhole, etc.) and dips (puddles, fords, etc.).

This integration issue has been deeply studied to fit with passenger cars requirements (Fig. 7) and will be validated on the demo-car at the final stage of the project. 

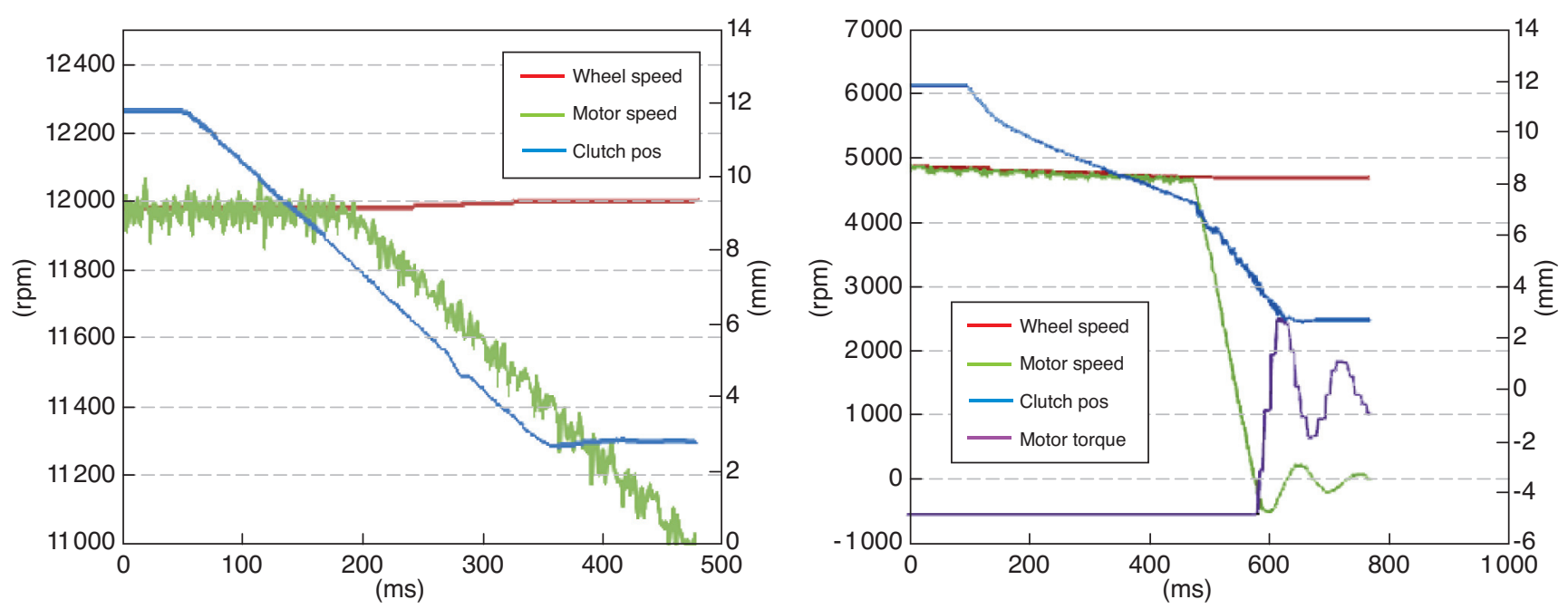

Figure 6

Clutch disengagement under nominal condition without torque at $85 \mathrm{~km} / \mathrm{h}$ (up) and under $5 \mathrm{Nm}$ torque (down).

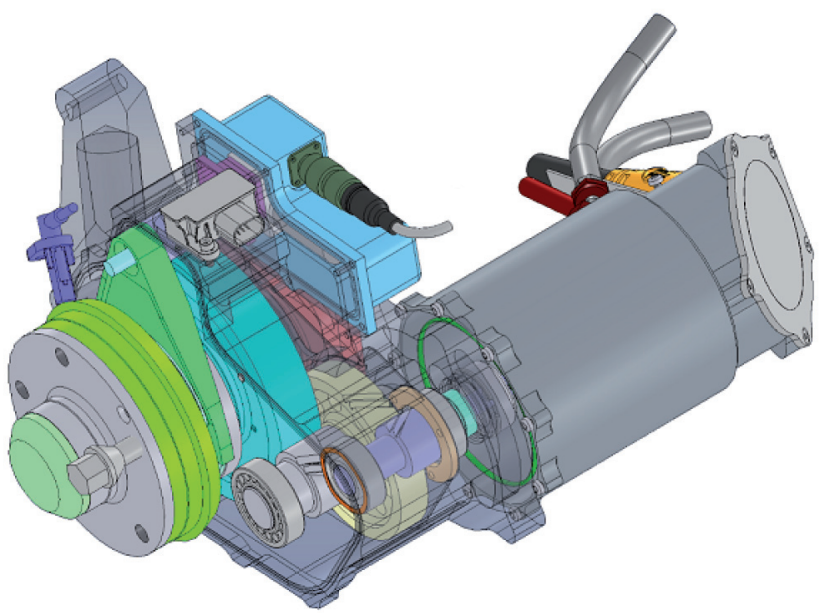

Figure 7

In-wheel motor and clutch integration.
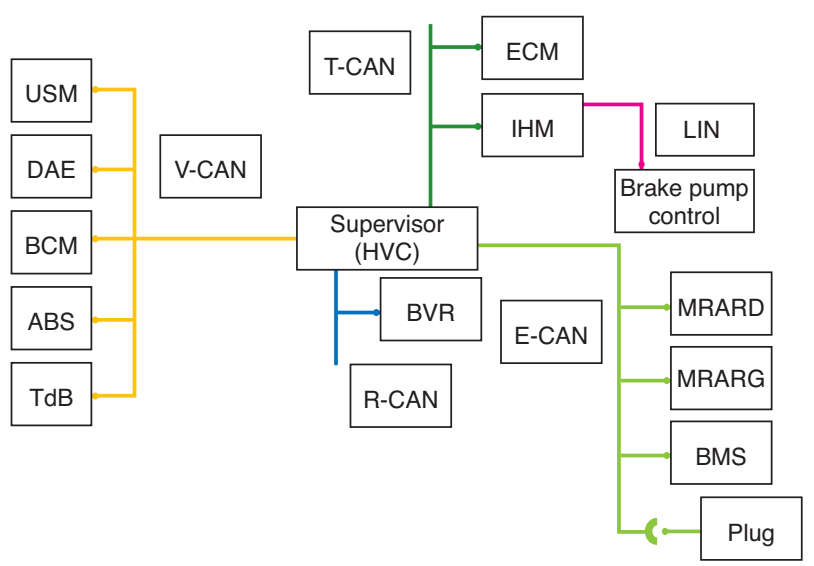

Figure 8

VelRoue inter-process communication.

\subsection{E/E Architecture}

The dual-mode architecture rests on the integration of two separate powertrains dedicated to each use but this still requires an inter-process communication as intrusive as on more typical hybrid vehicle. The supervisor should be the hub of all organs and must ensure the security of the system in case of failure, particularly related to the electric part.

\subsubsection{Inter-Process Communication}

Four CAN network have been defined to address the requirement of dual-mode operation (Fig. 8):

- V-CAN, network of conventional thermal vehicle;

- R-CAN between supervisor and gearbox;
- T-CAN between supervisor and thermal engine;

- E-CAN between supervisor, inverters and BMS.

In addition to assuming management and state of the vehicle in response to driver requests (driving mode, acceleration, braking), the supervisor acts as a common node and performs the gateway between the CAN networks in order to lure/ interpret all information depending on the desired mode.

\subsubsection{Safety Line}

For security reasons, in addition to CAN communication between the supervisor and the inverters, a hardware safety line was created to inhibit the inverters and disengage the in-wheel motors in case of fault detection by the supervisor or inverters during operation (Fig. 9). 


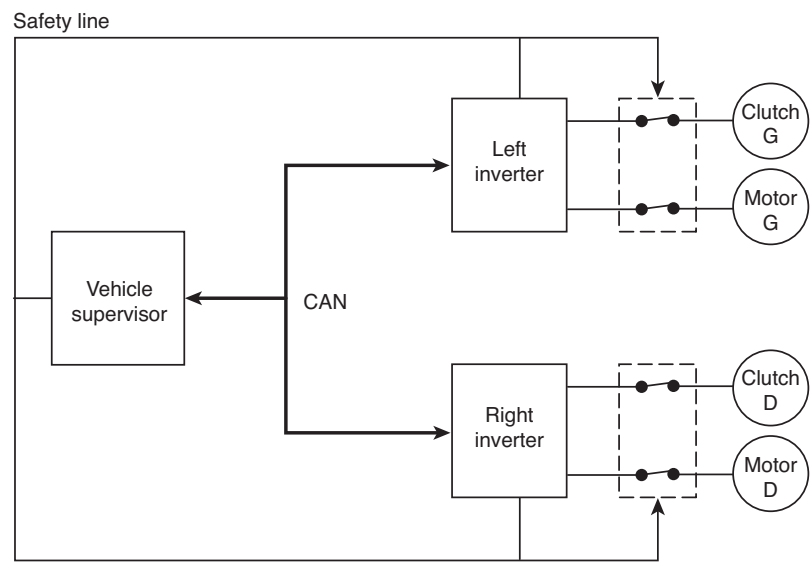

Figure 9

Safety line for in-wheel motors deactivation.

\section{VEHICLE SIMULATION}

This section presents the simulation platform and the models used to get the results discussed in the next sections.

\subsection{Simulation Platform}

In order to validate the algorithms of supervision and the vehicle behaviour, the supervisor and powertrain controllers have been coupled with a vehicle simulator aimed at representing the system dynamics and the inter-process communication as close as on real vehicle. The platform is then distributed between several models as shown in Figure 10. The vehicle simulator contains also different submodels:

- a quasistatic thermal engine model, with torque and consumption tabulated as a function of load and engine speed. The engine dynamics are represented to consider atmospheric and supercharging respective time responses;

- quasistatic electric motors models with torque and power losses tabulated and a second order dynamics;

- a battery equivalent-circuit model;

- a high-frequency transmission model (flywheel, clutch and gearbox) developed in AMESim platform;

- a high-frequency car body model with suspensions, wheels and tires developed in AMESim platform.

\subsection{Vehicle Dynamics}

The vehicle model developed in AMESim platform consists of the main vehicle mass to which the four wheels are attached via a suspension system. Only the longitudinal and pitch dynamics are represented which is sufficient to validate

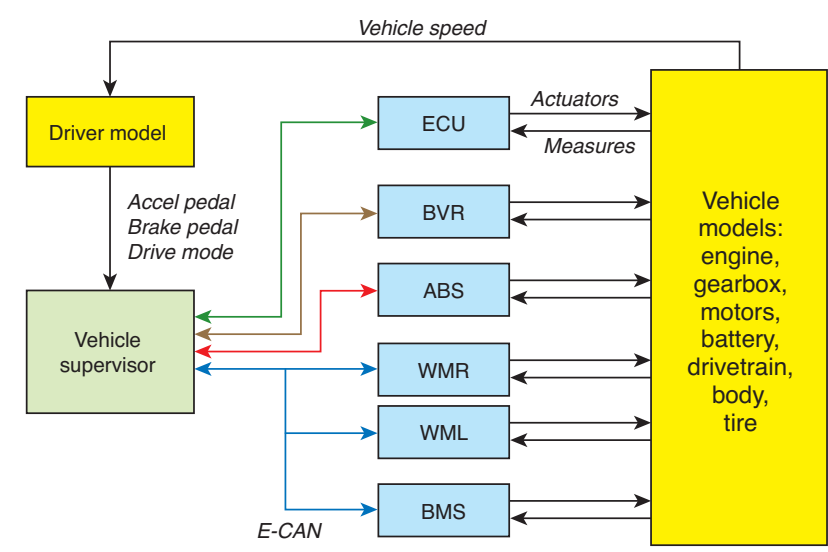

Figure 10

Schematics of the simulation platform.

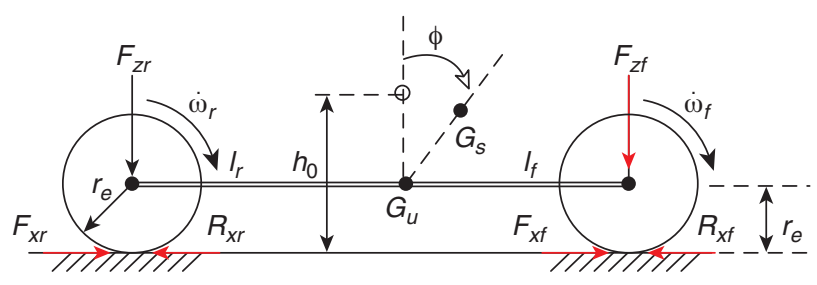

Figure 11

Vehicle dynamics model.

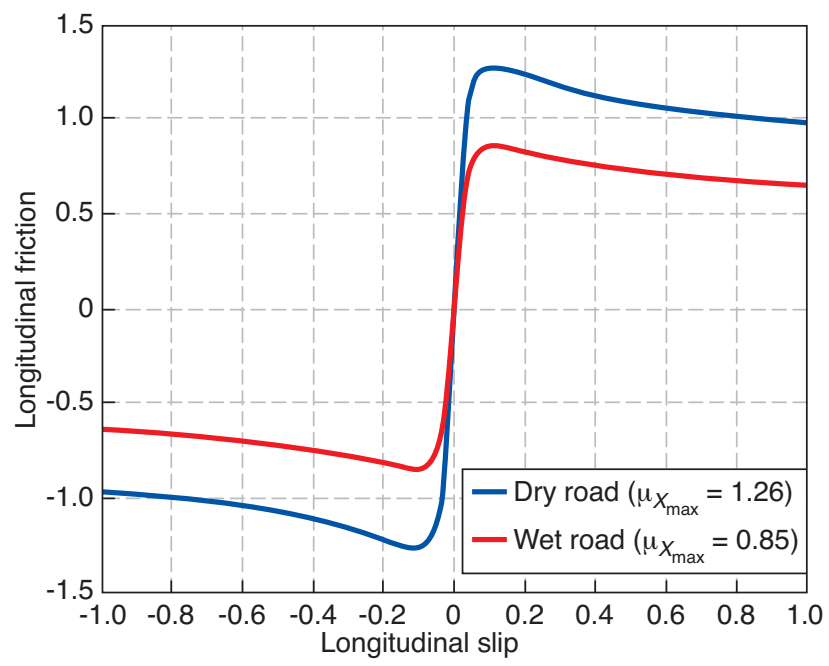

Figure 12

Pacejka models for longitudinal friction coefficient.

supervision strategies and the optimal use of in-wheel motors for regenerative braking and traction control as discussed in the next sections. Therefore, this model can easily be represented as a bicycle model, as shown in Figure 11. 
The pitch angle $(\Phi)$ is computed considering position of both centers of gravity of the suspended and unsuspended mass $\left(G_{u}\right.$ and $\left.G_{s}\right)$, suspension dynamics and load transfer that arises when the vehicle is accelerating or braking. Simplified system equations for longitudinal dynamics can be written as follows:

$$
\begin{aligned}
& m \dot{V}_{x}=F_{x}-F_{\text {aero }} \\
& I_{w} \dot{\omega}_{i}=T_{w i}-r_{e} F_{x i}-c_{r} F_{z i} \\
& F_{z i}=m_{w i} g \\
& F_{x i}=\mu_{x i} F_{z i} \\
& F_{x}=\Sigma F_{x i}
\end{aligned}
$$

where $m$ is the vehicle mass, $V_{x}$ the vehicle speed, $F_{x}$ the longitudinal force on vehicle, $F_{\text {aero }}$ the aerodynamic drag force, $I_{w}$ the wheel inertia, $\omega_{i}$ the wheel angular speed, $T_{w i}$ the wheel torque (coming from motor or engine and/or brake), $r_{e}$ the wheel radius, $F_{x i}$ and $F_{z i}$ the longitudinal and normal forces, $m_{w i}$ the equivalent mass (depending of center of gravity position and pitch) and $c_{r}$ the rolling resistance parameter.

The longitudinal tire friction coefficient between the road and the tire $\left(\mu_{x}\right)$ is function of the road conditions and the longitudinal slip $(\lambda)$ of the wheel defines as follow:

$$
\lambda=\frac{V_{x}-r_{e} \omega}{\max \left(V_{x}, r_{e} \omega\right)}
$$

A Pacejka formula [1] is classically used to model this friction coefficient (Fig. 12). It should be noted that limits of grip are known as maximum and minimum of this curve respectively in acceleration and deceleration and those limits are varying with road conditions.

\section{DUAL-MODE SUPERVISION}

The particularity of this dual-mode vehicle is that unlike a hybrid vehicle where the use of electrical energy is transparent, the choice of driving mode (thermal or electric) is left to the decision of the driver via a selector on the dashboard. A dedicated Human-Machine Interface (HMI) will provide all relevant information (for example state of charge and vehicle state) to assist the driver in mode selection. Nevertheless, control and supervision of both powertrains should be developed taking into account the desired performance (energy management, $\mathrm{CO}_{2}$ emissions, dynamic) and safety operation.

\subsection{Vehicle States}

In parallel of requested driving mode, the supervisor will have to manage different vehicle states according to functional state of the different components. If a failure appears somewhere, the supervisor must react to proposed or imposed, according to the malfunction criticism, an adapted back-up mode so that the driver can continue to safely use the vehicle or at worst case stop within security.
Table 2 presents the different vehicle states. NO is the nominal one without default. $\mathrm{N} 2$ and $\mathrm{N} 4$ able to drive the car even in case of a malfunction. In state N2, the safety line will be active and the car could be used as a conventional thermal vehicle. In state N4, the gearbox is declutched and the car can be used only in electric driving mode. States D3, D4 and P are back-up mode in case of a malfunction disabling the use of the vehicle in normal conditions in both driving mode.

TABLE 2

VelRoue vehicle states

\begin{tabular}{l|l|l}
\hline No. & \multicolumn{1}{|c|}{ Name } & \multicolumn{1}{|c}{ Comment } \\
\hline N0 & Nominal & $\begin{array}{l}\text { Thermal traction OK } \\
\text { Electric propulsion OK }\end{array}$ \\
\hline N2 & Thermal & $\begin{array}{l}\text { Thermal traction OK } \\
\text { Electric propulsion default }\end{array}$ \\
\hline N4 & Electric & $\begin{array}{l}\text { Thermal traction default } \\
\text { Electric propulsion OK }\end{array}$ \\
\hline D3 & Limited speed & In thermal mode if clutch malfunction detected \\
\hline D4 & Drive to stop & If drive selector KO and/or gearbox stuck in gear \\
\hline P & Failure & Vehicle stop \\
\hline
\end{tabular}

In the next sections of this paper, we will consider only the nominal state NO.

\subsection{Functional Behaviour in Nominal State}

\subsubsection{Thermal Driving Mode}

As seen in previous section, in order to optimize energy management and $\mathrm{CO}_{2}$ emissions, both powertrains are used in nominal vehicle state when the driver select the thermal driving mode (Fig. 13):

1 During pull-away, the 2nd gear is engaged and motors assist engine with a ramping strategy.

2 During driving and as the vehicle speed is below the limit for declutching, electric motors assist thermal engine in transient under stability criterion.

3 During braking or deceleration, in-wheel motors are used for energy recovery in coordination with friction brake.

4 In-wheel motors declutching are done crossing a vehicle speed of $90 \mathrm{~km} / \mathrm{h}$ and clutching below $80 \mathrm{~km} / \mathrm{h}$.

In case of low state of charge level, the in-wheel motors assistance during pull-away and driving will be disabling. Only the energy recovery ability would be let active.

\subsubsection{Electric Driving Mode}

In this mode, the thermal engine is stopped and only the electric powertrain is used (Fig. 14):

- vehicle pull-away and drive are fully managed by in-wheel motors; 


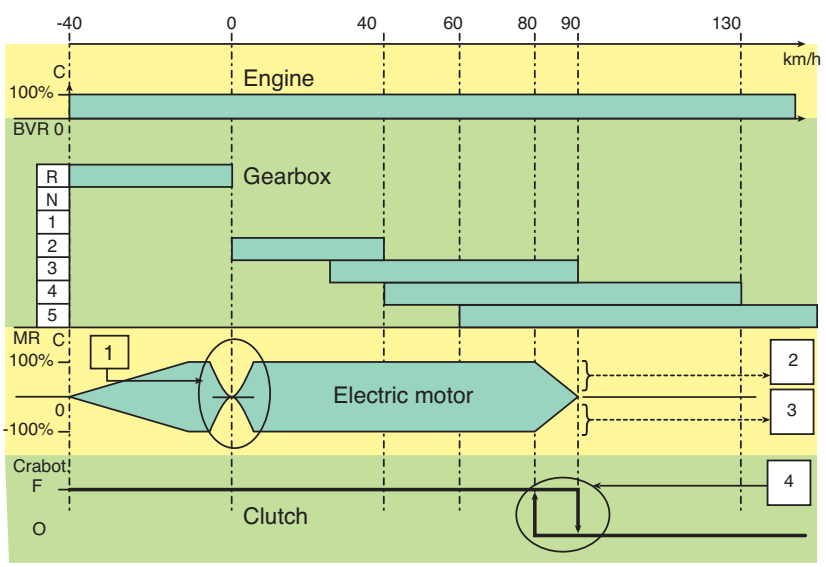

Figure 13

Operation diagram in thermal driving mode.

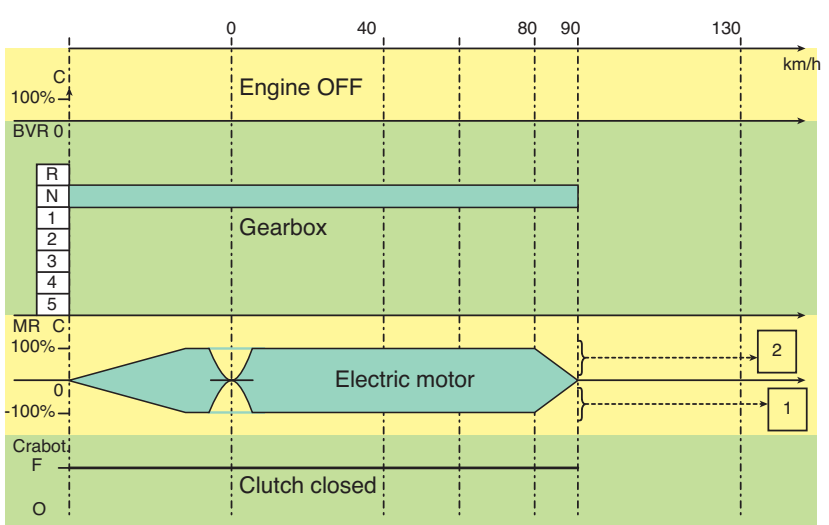

Figure 14

Operation diagram in electric driving mode.

- overall motor operating range is available during driving and braking in coordination with friction brake.

In case of low state of charge level, a torque limitation strategy will apply and driver will be informed he has to switch in thermal driving mode.

\subsection{Torque Distribution}

The stability of the trajectory of a vehicle is strongly related to the behaviour of the rear axle. In nominal operation, the supervision and control system of the torque applied to the rear wheels must maintain good traction when accelerating or braking. In addition, the objective of a device which participates in the increase of autonomy (electric mode) and the reduction of $\mathrm{CO}_{2}$ emissions (thermal mode) are to optimize energy recovery in the rear wheels during deceleration and braking.
Therefore, maintaining vehicle stability under these conditions will not only affect the in-wheel motor but the entire system: the motor and the friction brake, which will require the establishment of an upstream supervision.

\subsubsection{Driving Case}

As seen in previous section and in Figure 13, when the driver select the thermal driving mode, in-wheel motors are used to assist the engine during pull-away and transient phases. A power split strategy has been developed and integrated in the supervisor to satisfy those requirements while limiting the actuators torque on the two axles to maintain a good tire/road friction. This strategy is based on the fact that during transients both the engine and the electric motor can be used to fulfil the driver request:

$$
T_{\text {wheel sp }}=\sum T_{w i s p}=\sum T_{m i s p}+G e a r \cdot T_{e s p}
$$

where $T_{\text {wheel } s p}$ is the total driver torque request at the wheels, $T_{w i s p}$ is the torque setpoint for the wheel $i, T_{m i s p}$ is the torque setpoint for the motor $i$ (on rear wheels), Gear is the gear ratio engaged and $T_{e s p}$ the engine torque setpoint.

Furthermore to maintain a good tire/road friction, the torque requests for each axle are saturated to not exceed the limit of friction given by the traction control or ABS systems:

$$
\left\{\begin{array}{l}
\mu_{f}=\left(\frac{F_{x}}{F_{z}}\right)_{\text {front }}=\frac{\text { Gear } \cdot T_{e s p}}{r_{e} \cdot F_{z f}}<\mu_{\text {max }} \\
\mu_{r}=\left(\frac{F_{x}}{F_{z}}\right)_{\text {rear }}=\frac{\sum T_{m i s p}}{r_{e} \cdot F_{z r}}<\mu_{\text {max }}
\end{array}\right.
$$

where $\mu_{f}$ and $\mu_{r}$ are the instantaneous friction coefficient of the front and rear tires, $F_{x}$ and $F_{z}$ are the longitudinal and normal forces applied to the front and the rear wheels and $\mu_{\max }$ is the limit friction coefficient.

Figure 15 shows the assistance of electric motors during acceleration. First, the electric motors provide all the torque needed to pull-away the vehicle. When the engine is started and the second gear ratio is engaged, the electric motors partially assist the engine until it provides the request wheel torque. During the gearbox up shift, the electric motors are also used to compensate the engine torque lag due to the clutch opening. Those results also shows that the torque distribution satisfies a good tire/road friction since the instantaneous friction coefficient of the front and the rear tires are lower than the limit friction coefficient $\mu_{\max }$ (equal to 1.2 for a dry road).

\subsubsection{Braking Case}

During braking, in-wheel motors can be used to maintain the vehicle stability while optimizing energy recovery. 

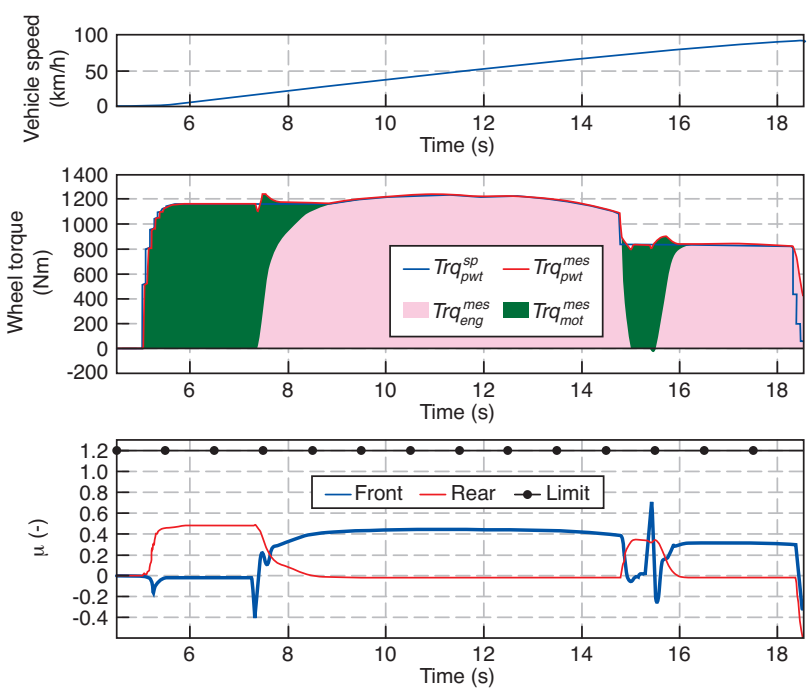

Figure 15

Powertrain torques distribution in thermal driving case.
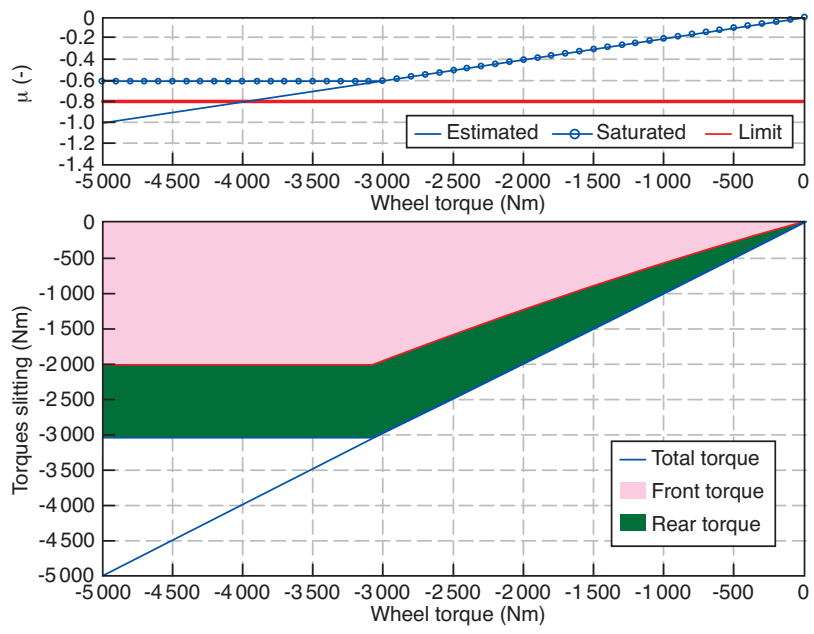

Figure 16

Axle torque distribution for braking case.

The wheel torque applied during braking is decomposed as follows:

$$
T_{\text {wheel sp }}=\sum T_{\text {mi sp }}+T_{\text {brake f }}+T_{\text {brake } r}
$$

where $T_{\text {wheel }}$ is the total driver torque request, $T_{m i s p}$ is the torque setpoint for the motor $i$ (on rear wheels), $T_{\text {brake } f}$ and $T_{\text {brake } r}$ are the hydraulic braking torques on each axles.

The engine torque has been neglected since during braking phases the engine should be declutched to ensure a maximum energy recovery by the motors. In a first step, we compute the torque splitting between both axles and in a second one, depending on the communication with the ABS system control, we distribute the rear axle torque to the electric motors and the hydraulic brakes.

\section{Axles torque splitting}

From the total braking torque requested to the wheel, the static weight distribution of the car and the dynamic mass transfer in deceleration, we can compute the normal forces applied on the front and the rear axles [7]:

$$
\begin{aligned}
& F_{z f}=\frac{m \cdot g \cdot l_{r}}{2 l}-\frac{h_{0} \cdot T_{\text {wheel } s p}}{2 l \cdot r_{e}} \\
& F_{z r}=\frac{m \cdot g \cdot l_{f}}{2 l}+\frac{h_{0} \cdot T_{\text {wheel } s p}}{2 l \cdot r_{e}}
\end{aligned}
$$

To maintain the stability of the vehicle, the objective is to keep the friction on the rear wheels higher than on the front wheels:

$$
-\mu_{\max }<\left(\frac{F_{x}}{F_{z}}\right)_{\text {front }} \leq\left(\frac{F_{x}}{F_{z}}\right)_{\text {rear }}<0
$$

From this condition and Equations (10) and (11), the longitudinal forces applicable on each axle are:

$$
\begin{gathered}
F_{x f} \leq \frac{T_{\text {wheel } s p}}{m \cdot g \cdot r_{e}} F_{z f}<0 \\
0<\frac{T_{\text {whel } s p}}{m \cdot g \cdot r_{e}} F_{z r} \leq F_{x r}
\end{gathered}
$$

On our specific case with in-wheel motors on the rear axle, we have interest to apply a maximum torque on the rear axle to maximize the energy recovery. Because of this specific condition, we will try to maintain the same friction on the rear and the front axle. Then, from previous equations and the value of the maximum braking torque on the front axle, we obtain a static map providing the axle torques splitting function of the maximum friction coefficient $\mu_{\max }$ and the requested total wheel torque. Figure 16 shows the axle torque distribution for different values of this requested total wheel torque during braking. The maximum friction coefficient used in this case is 0.8 . One can notice that the minimum total wheel torque applicable to this vehicle is then near to $-3000 \mathrm{Nm}$. Indeed, the two hydraulic brakes on the front axle have reached their maximum values $(-1000 \mathrm{Nm})$ and the rear brake torque is saturated to keep the same friction according to (12). In this condition the minimum value of the tire friction isn't reached, the front brakes are saturated before.

\section{Rear torque distribution between the wheel motors} and the hydraulic brakes

Once computed the requested rear torque, we have the possibility to fulfil it with two actuators: the hydraulic brakes and the in-wheel motors. The solution depends on the possibility to decouple the position of the brake pedal to the hydraulic brakes pressure. The simplest one without any modifications 

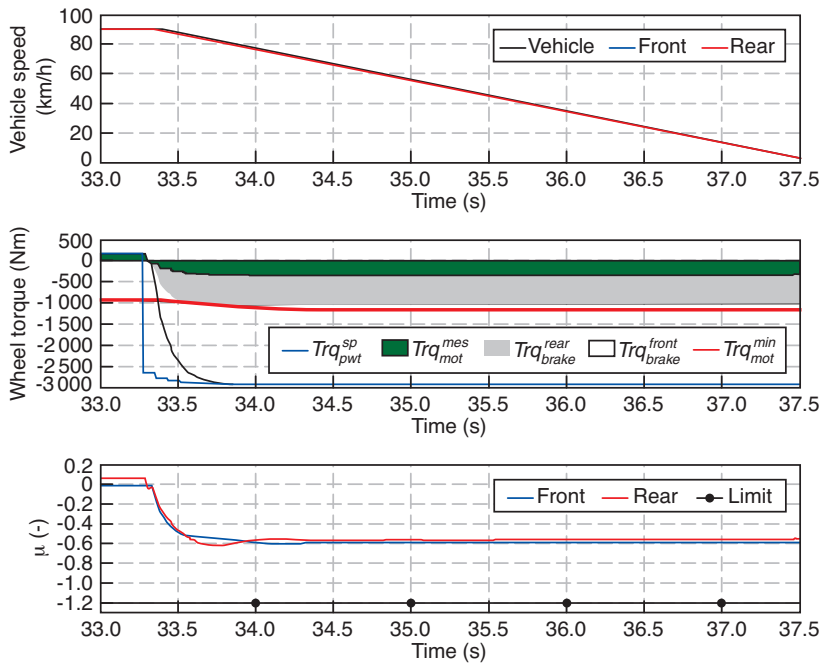

Figure 17

Torque distribution during braking on a dry road with a constant wheel motor torque.

on the ABS system is to apply a constant negative torque to the wheel motors during a deceleration. This braking torque should represent the engine braking torque apply during accelerator pedal release. The disadvantage of this solution is a lake of energy recovery by the electric motor. Figure 17 shows a deceleration obtain with this strategy. As explained before, the wheel motors apply a constant torque which is widely lower than the minimum motor torque. A lot of energy is dispersed as heat by the rear hydraulic brakes (in gray) and could be recovered by the in-wheel motors. On the other hand, the tire frictions are well maintained similar on the rear and front axle.

An interesting use of the wheel motors is to recovery the maximum electric energy during braking phases while control the friction on the rear axle. Figure 18 shows the same braking phase than Figure 17 but with a maximum use of the electric motors to fulfil the requested rear torque. We can see on this specific braking, that the wheel motors quite realize the rear torque request. The rear brakes are then only slightly used at the beginning of the braking since the rear torque setpoint is lower than the maximum wheel motor torque.

\section{Behaviour in low friction conditions}

As seen previously, the axles torque splitting strategy can use an estimation of friction limit during braking to limit the torque on each axle according to Equation (12). Figure 19 shows results of this strategy in low friction conditions. This ensures vehicle stability by meeting the two constraints:

Keeping the same friction coefficient on both axles while remaining bellow the road limit. Furthermore, one can notice
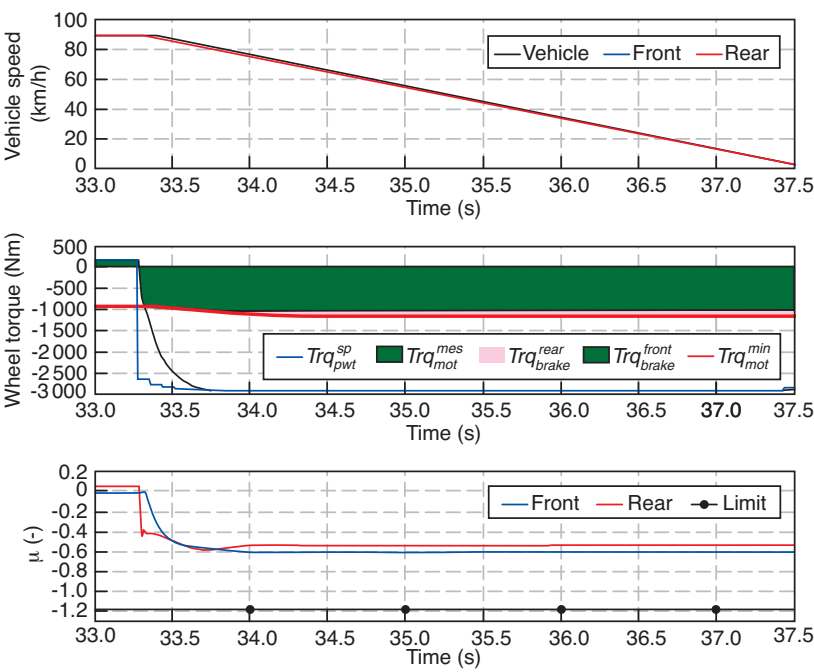

Figure 18

Torque distribution during braking on a dry road with full control of the braking system.
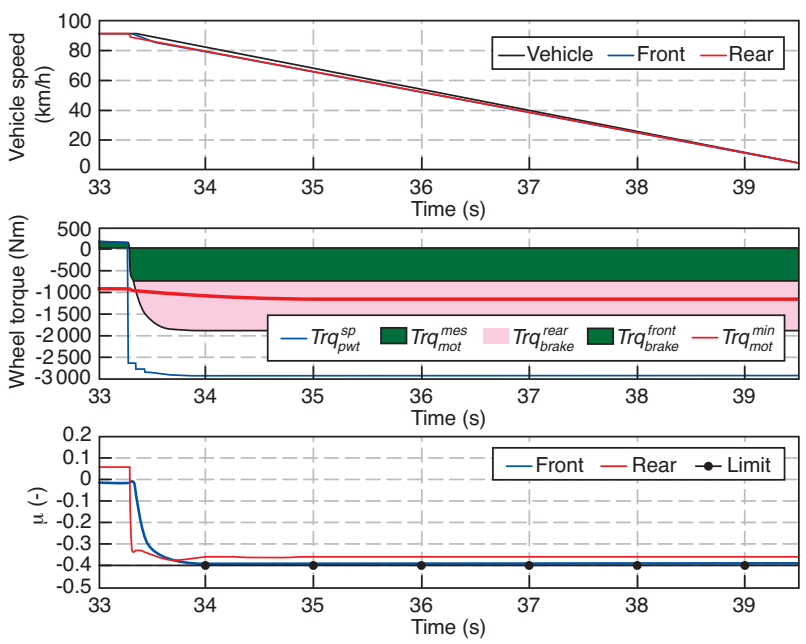

Figure 19

Torque distribution during braking on a wet road with full control of the braking system.

that the rear torque distribution strategy able to optimize energy recovery using only the in-wheel motors.

\section{WHEEL SLIP CONTROL}

Traction control and ABS systems are main components in providing safety behaviour and achieving desired vehicle grip in overall conditions. In conventional vehicles, two main actuators accomplish those functions, the combustion engine and the hydraulic brake system. It imposes different solutions of control adapted to different actuators dynamics [2, 3]. Using in-wheel motors provides new opportunities to control 
the torque to the wheel with a fast response time [4]. It could then be use as the main actuator to ensure safety vehicle motion in both acceleration and deceleration.

\subsection{Parameter Estimation}

With a classical architecture, the estimation of the friction force is complex because of immeasurable parameters, as the torque applied to the wheel and need complex observers $[5,6]$. The torque output of the motor can be easily calculated from its current. This merit makes it easier to estimate the driving and braking force between the tire and the road surface and then the maximum friction coefficient according to varying road conditions.

\subsubsection{Longitudinal Friction Estimation}

The normal forces applied on the front and rear wheels may be pretty well approached by considering pitch rate and static weight distribution [7]. To estimate the longitudinal friction force for a wheel, we took advantage of the knowledge of the torque and the wheel velocity in motion Equation (2):

$$
F_{x i}=\frac{1}{r_{e}}\left(T_{i}-I \dot{\omega}_{i}-c_{r} F_{z i}\right)
$$

where $c_{r}$ is a rolling resistance parameter.

The instantaneous friction coefficient $\mu_{x}$ can then be directly estimated according to Equation (8).

\subsubsection{Maximum Friction Estimation}

As seen in Section 2.2, the limit of friction to prevent wheel slip during driving or braking is the maximum of the curve $\mu_{x}-\lambda$ depending on road surface conditions. To optimize slip control strategies, it is helpful to get a relevant estimation of this limit. As Pacejka model is highly complex and nonlinear, a simpler Dugoff tire model [8] will be used. It has the advantage to represent longitudinal friction coefficient related to its maximum and depends only of two parameters, $K_{x}$ the longitudinal stiffness coefficient and $\alpha$ a weight factor:

$$
\begin{aligned}
& \mu_{x}=f(\varphi) K_{x} \lambda \\
& f(\varphi)=\left\{\begin{array}{ccc}
(2-\varphi) \varphi & \varphi<1 \\
1 & \varphi \geq 1
\end{array} \quad \varphi=\alpha \frac{\mu_{x \max }}{2\left|K_{x} \lambda\right|}\right.
\end{aligned}
$$

Considering the nonlinear zone case, $\mu_{x \max }$ can be expressed as the solution of a second order equation:

$$
\mu_{x \max }=\frac{2}{\alpha}\left(K_{x} \lambda \pm \sqrt{K_{x} \lambda\left(K_{x} \lambda-\mu_{x}\right)}\right)
$$

The sign in expression depending of the sign of longitudinal $\operatorname{slip} \lambda$.

To adapt this estimation to the road conditions, an approach is to use the extended braking stiffness (XBS, defined as the derivative of the friction coefficient) $[9,10]$. It needs to be close to this limit to adapt accurately. It has been preferred to adapt on-line $K_{x}$ and $\alpha$ parameters with least-squares method respectively during linear and nonlinear parts of the curve. One must notice two important results (Fig. 20):

- on a wide range of road conditions ( $\mu_{x \max }$ from 1 to 0.4$)$ the $\alpha$ parameter range is low (from 1.09 to 1.16 );

- in each case, maximum friction estimation is not constant due to simplification between Pacejka and Dugoff models. It aims to get overestimation before the limit (circle mark) and underestimation after. The estimation provides an accurate maximum value on the limit as far as parameters are well adapted.
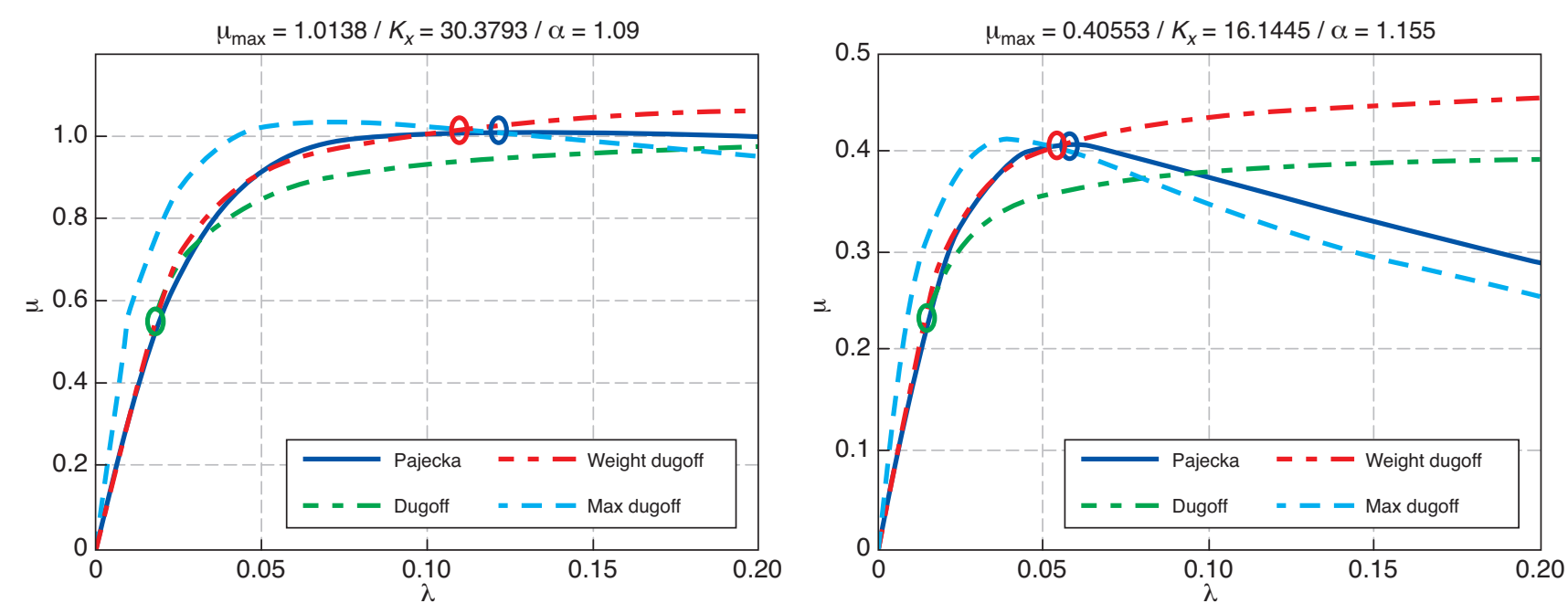

Figure 20

Maximum friction estimation in dry (left) and wet (right) road. 
Those results invoke a good robustness to road variations and the dynamic behaviour is considered to be on the safe side in an emergency situation.

\subsection{Sliding Mode Control}

With a classical ABS system, because of highly nonlinear behaviour of friction curves and the latency of the hydraulic actuators, the existing control strategies are often based on sliding-mode control, as it guarantee the robustness of the system against changing working conditions $[11,12]$ and rely directly on the longitudinal slip with often a conservative fixed threshold. Taking advantage of their fast response time and the knowledge of their output torque, the electric motors allow applying a control on the friction coefficient, while considering the road conditions.

A feedback sliding mode control law is designed such that it will guarantee the system trajectory moving toward the sliding surface and staying on it. In order to take advantage of the previous $\mu_{x}$ and $\mu_{x \max }$ estimations, a sliding surface $S=\operatorname{sign}(X B S) .\left(\mu_{x \max }-\mu_{x}\right)$ has been selected and motivated in [10]. The sliding control law computes from Equation (2) the maximum wheel torque to stay under optimal friction conditions:

$$
T_{s}=I_{w} \dot{\omega}+F_{z}\left(r_{e} \mu_{x \max }+c_{r}\right)+\operatorname{sign}(S) \int k S . d t
$$

As presented in Section 3.3, the supervisor computes torque distribution in both driving and braking case in order to meet traction and optimal energy recovery requirements. Considering that the anti-slip control is assumed by in-wheel motors on rear axle, one can computes electric motor torque command:

$$
\begin{aligned}
& \text { if } \lambda>0, T_{\text {emot } s p}=\min \left(T_{\text {emot req }}, \frac{T_{s}}{R}\right) \\
& \text { else, } T_{\text {emot sp }}=\max \left(T_{\text {emot req }}, \frac{T_{s}-T_{\text {brake req }}}{R}\right)
\end{aligned}
$$

It shows how anti-slip control is applied with electric motors taking in account the hydraulic braking.

\subsection{Results}

Next section presents results of friction estimation and wheel slip control in two characteristic cases:

- adaptation to varying low friction conditions;

- emergency braking.

\subsubsection{Low Friction Conditions}

In electric driving mode and in both driving and braking case, the wheel slip controller aims to limit in-wheel motors torque to assume both TCS (traction control) and ABS
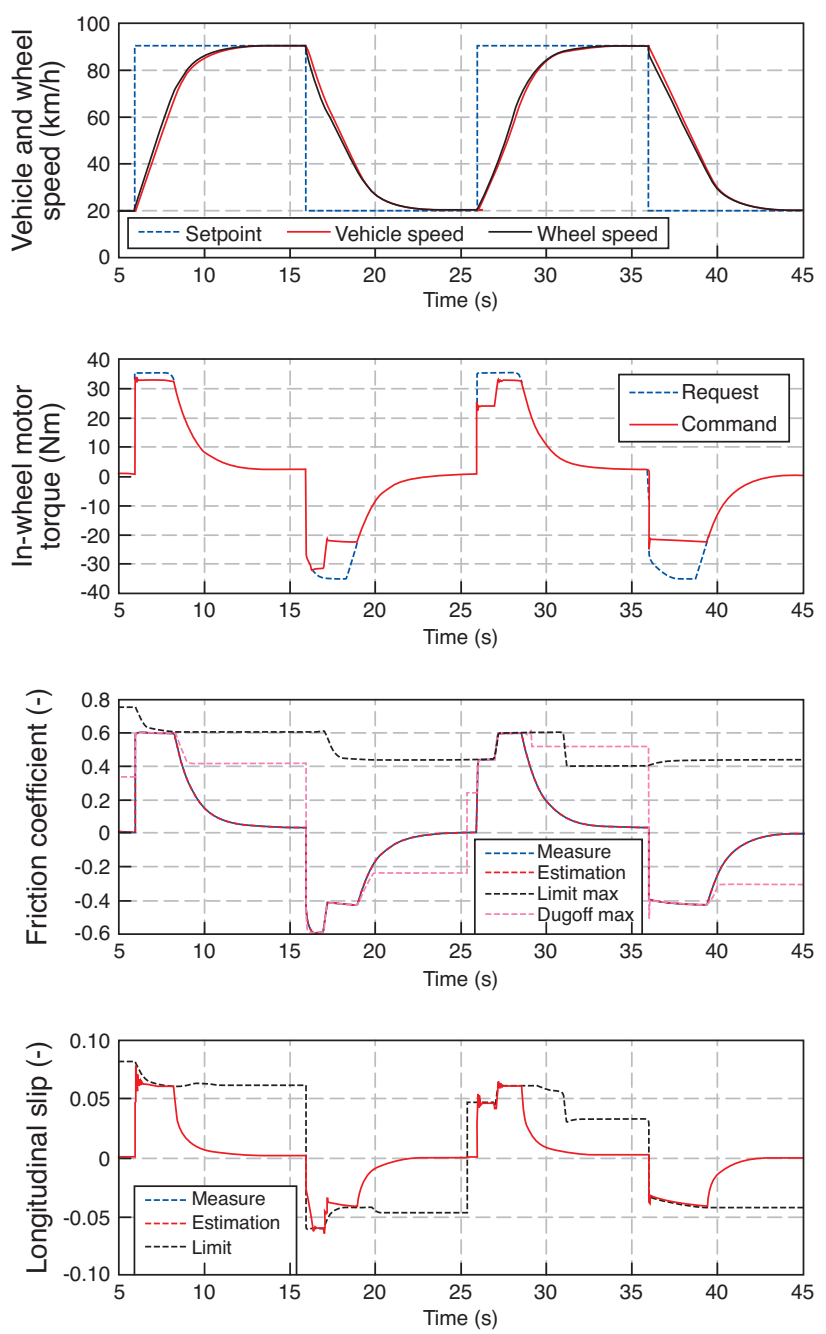

Figure 21

Wheel slip control in both driving and braking case while changing road adherence conditions.

functions, while taking in account changing road conditions. To validate the behaviour of friction estimation and control, successive acceleration and braking have been simulated while changing road adherence conditions (Fig. 21).

The maximum friction coefficient $\mu_{x \max }$ is switched from 0.6 to 0.4 and vice versa at 16,26 and $30 \mathrm{~s}$. One can first notice the relevant dynamic estimation of maximum friction coefficient from Dugoff model (17) in transient and during slip control in both acceleration and braking. Particularly when the road condition is changing during transient (at 16 and $26 \mathrm{~s}$ ) this estimation fits in real time. Then, the control achieves to track this value when needed (if estimated friction coefficient $\mu_{x}$ tends to exceed this limit) by limiting the torque requested by the supervisor. The wheel slip is then limited to get optimal grip to the road while preventing wheel lock. 


\subsubsection{Emergency Braking}

During emergency braking, the ABS system is triggered to prevent wheels from blocking. The latency of the hydraulic actuators causes a on-off behaviour of the controller with an oscillation around the optimal grip. As presented before, one valuable feature of the use of in-wheel motors is to improve wheel slip control while optimizing regenerative braking. Next results show how this anti-slip controller can also prevent wheels from blocking with deactivated ABS system on the rear wheels.

An emergency braking on dry road has been simulated in three different cases (Fig. 22):

- the supervisor computes maximum braking torque for both electric and hydraulic actuators and wheel slip controller is deactivated. In this case, the wheel blocks and the slip is not control anymore;

- the supervisor computes maximum braking torque for both actuators and wheel slip controller is assumed by limitation of electric wheel torque to prevent slip is then fully assumed by the electric motor. The longitudinal slip is well controlled with a limited oscillation but the generative braking is not optimal anymore. In some case, in-wheel motor torque could even reach the actuator saturation;

- the supervisor uses maximum friction coefficient estimation to compute feedback torque distribution between electric and hydraulic actuators (Sect. 3.3.2). It reduces the hydraulic brake torque to keep in-wheel motor torque close to its maximum and optimize regenerative brake while keeping longitudinal slip control. One can notices than in this case the supervisor acts as a preventive control, improving transient behaviour.

\section{CONCLUSION}

In this paper new dual mode architecture for electrified vehicle using a conventional thermal powertrain on the front axle and in-wheel motors on the rear axle has been proposed. The design of both electrical and thermal powertrains has been optimized considering their respective urban and extra-urban use in order to combine the advantages of an electric vehicle in urban conditions (no pollutants, $\mathrm{CO}_{2}$ emissions and noise), with a significant preservation of the range autonomy of a conventional thermal vehicle on road. Particularly, technological issues related to the use of in-wheel motors have been addressed, such as their integration in a restricted and stressed area.

In a second part, the paper focuses on vehicle supervision according to driving mode and on a valuable feature of the use of in-wheel motors. The proximity of electric motors to the wheels and the knowledge of their output torque help in regenerative braking optimization and wheel slip control. During braking, being intrusive on hydraulic brake system
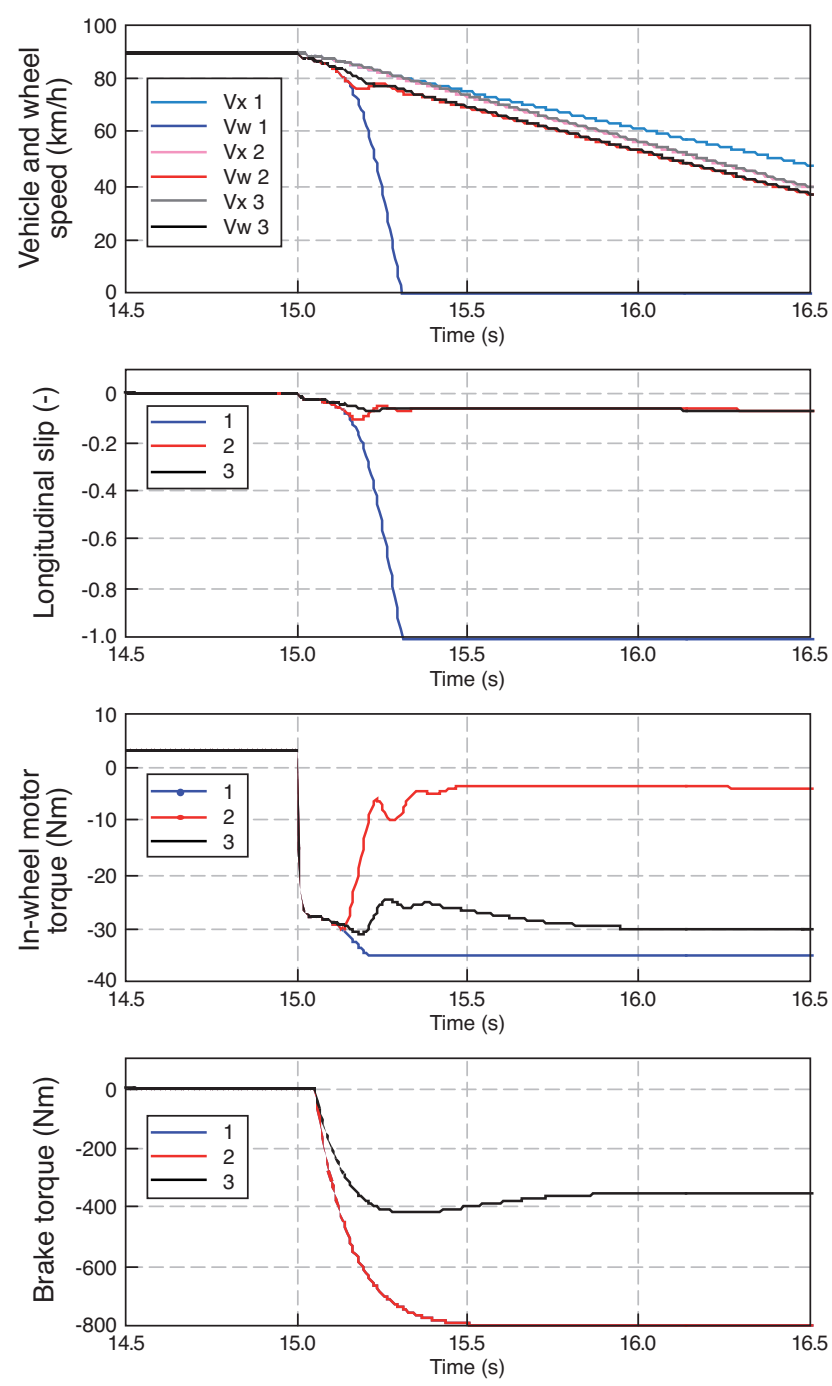

Figure 22

Wheel slip control during an emergency braking with both electric and hydraulic actuators.

able the supervisor to manage torque distribution between axles to maintain vehicle stability and between both electric and hydraulic actuators on rear axle in order to optimize the use of in-wheel motors. Finally, we show the ability to control the wheel slip with accuracy on maximal friction point and whatever the road adherence condition, using electric motors instead of classical hydraulic actuators.

\section{REFERENCES}

1 Pacejka H., Baker E. (1991) The magic formula tyre model, 1st International Coll. Tyre Models Vehicle System Analysis.

2 Denny M. (2005) The Dynamics of Antilock Brake Systems, Eur.J.Phys. 26, 1007-1016. 
3 Savaresi S.M., Tanelli M. (2010) Active Braking Control Systems Design for Vehicles, Springer.

4 Hori Y., Toyoda Y., Tsuruoka Y. (2009) A Novel Traction Control without Chassis Velocity for Electric Vehicles, EVS24, International Electric Vehicle Symposium, Stavenger, Norvège.

5 Ono E., Asano K., Sugai M., Ito S., Yamamoto M., Sawada M., Yasui Y. (2003) Estimation of automotive tire force characteristics using wheel velocity, Control Eng. Pract. 11, 12, 13611370.

6 Yi J., Alvarez L., Claeys X., Horowitz R. (2003) Emergency braking control with an observer-based dynamic tire/road friction model and wheel angular velocity measurement, Veh. Syst. Dyn. 39, 2, 81-97.

7 Jazar R.N. (2008) Vehicle dynamics: Theory and Applications, Springer.

8 Dugoff H., Fancher P.S., Segel L. (1969) Tire performance characteristics affecting vehicle response to steering and braking control inputs, Technical Report, Highway Safety Research Institute, Ann Arbor, MI.
9 Villagra J., d'Andrea-Novel B., Fliess M., Mounier H. (2011) A diagnosis-based approach for tire-road forces and maximum friction estimation, Control Eng. Pract. 19, 2, 174-184.

10 Geamanu M., Cela A., Le Solliec G., Mounier H., Niculescu S. (2011) Road condition estimation and longitudinal control for electric vehicles, 11th ICCAS, Gyeonggi- do, Republic of Korea.

11 Chin Y.K., Lin W.C., Sidlosky D.M., Sparschu M.S. (1992) Sliding-mode ABS wheel slip control, American Control Conference, Chicago.

12 Kayacan E., Oniz Y., Kaynak O. (2009) A Grey System Modelling Approach for Sliding-mode Control of Antilock Braking System, IEEE Trans. Ind. Electron. 56, 8, 3244 - 3252.

Final manuscript received in April 2012 Published online in March 2013 or distributed for profit or commercial advantage and that copies bear this notice and the full citation on the first page. Copyrights for components of this work owned by others than IFP Energies nouvelles must be honored. Abstracting with credit is permitted. To copy otherwise, to republish, to post on servers, or to redistribute to lists, requires prior specific permission and/or a fee: Request permission from Information Mission, IFP Energies nouvelles, fax. +33147527096 , or revueogst@ifpen.fr. 